TEODORO FERNÁNDEZ ARQUITECTOS

TEODORO FERNÁNDEZ

Profesor Titular, Escuela de Arquitectura,

Pontificia Universidad Católica de Chile,

Santiago, Chile

?

Copiapó, Chile

2018

Palabras clave

Infraestructura

Paisaje

Ciudad

Renaturalización

Cauce
La oposición entre infraestructura y paisaje natural es sólo aparente. A su vez la arquitectura no sólo puede 'suavizar' el encuentro entre ambas, sino también repensarlo de formas radicales. En este caso, ante el encargo de un proyecto de infraestructura hidráulica, la arquitectura opera 'renaturalizando' el cauce de un río. Así, se demuestra que no es la infraestructura la que destruye paisajes, ecosistemas y comunidades, sino más bien la falta de cuidado en su diseño.

U bicada al sur del desierto de Atacama, la ciudad de Copiapó se funda en la ribera norte del valle del río del mismo nombre. En las últimas décadas, sin embargo, la ciudad se ha expandido a la ribera sur, ocupando un área agrícola de más de 200 hectáreas. A pesar de que el río no trae agua hace años - la ciudadanía recuerda con nostalgia el pequeño cauce que regaba huertos y donde los niños se bañaban - para Copiapó el río es el elemento que hace evidente la escala territorial de la ciudad. Pero el degradante uso que se le ha dado al cauce - lugar para botar escombros de construcción y relaves mineros - lo transformó en un espacio marginal que acentuaba la división de la ciudad e interrumpía la continuidad del cauce como espacio verde.

Cuando iniciamos los trabajos en el 2010, estaban a medio construir las obras de 'defensa' del río ante las grandes crecidas (un período de ioo años). Ellas no sólo ignoraban si el tramo era urbano o rural, sino también la condición natural del río en épocas de sequía. Así, una mal entendida ingeniería dejaba al río como un depósito de basura, escombros y relaves mineros en el centro de la ciudad, dividiéndola, pero con defensas. La solución estándar lo transformaba en un cauce con un fondo plano y muros laterales que contienen
PAULINA COURARD

Académica, Escuela de Arquitectura, Pontificia Universidad Católica de Chile, Santiago, Chile 


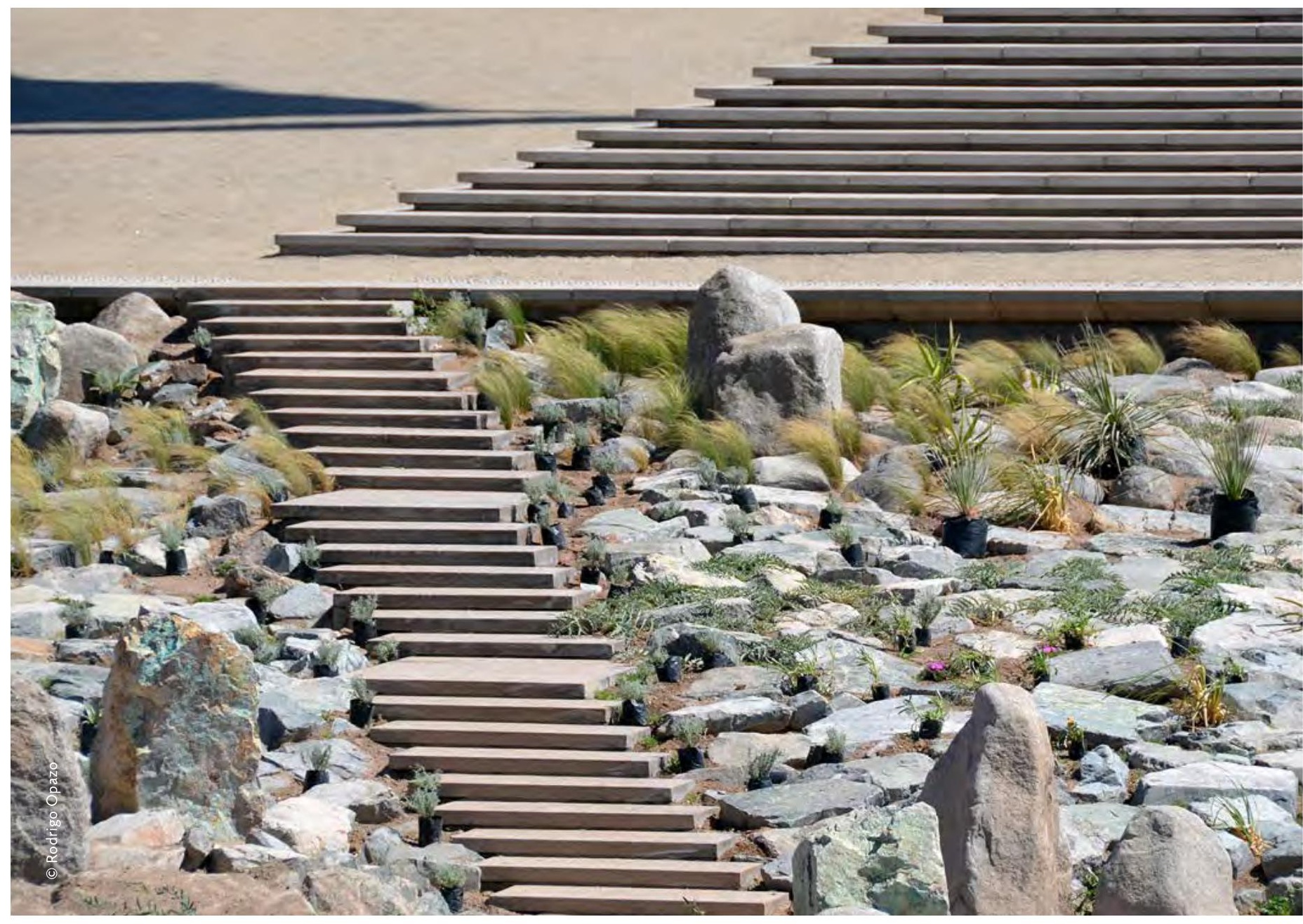

la crecida, pero impiden el acceso a las riberas. Un río transformado en canal.

En ese contexto, considerando tanto los problemas de degradación como hidráulicos del río Copiapó, el proyecto propone su renaturalización e integración como espacio abierto al uso cotidiano; es decir, que funcione como espacio público en todas las épocas del año, tanto en momentos de sequía como de grandes crecidas. El proyecto parque Kaukari enfrenta estos aspectos en una extensión de $3,5 \mathrm{~km}$, bajo el argumento de que el río no sólo debe servir como elemento de drenaje de la cuenca, sino que debe convertirse en centro de la ciudad que la vincule al valle, la región y su paisaje.

\section{Propuesta hidráulica}

Propusimos una sección tipo para diversos caudales que, a la vez, permitiera actividades de flora, fauna y humanas. Además, estudiamos más de ioo cortes con las diferentes variaciones, meandros, anchos, pendientes, riberas y contenciones para responder a las diversas situaciones.

Para el área del parque Kaukari, propusimos dividir la sección transversal del río en al menos cuatro espacios. El más profundo e interior es el cauce permanente, diseñado para la crecida de 2 años, con anchos entre 6 y 

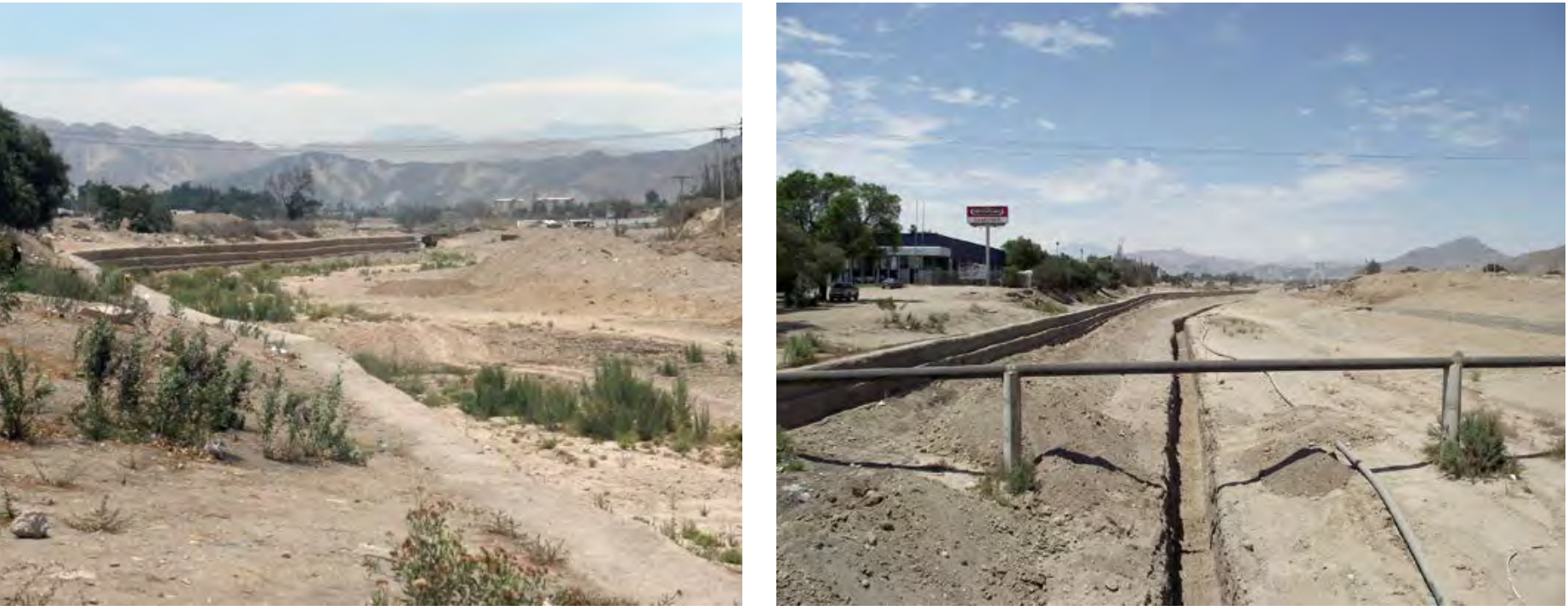

Cauce del río en estado previo. / River bed,

previous state.

(c) Teodoro Fernández
Io metros. Aquí se despeja el lecho natural y el fondo es prácticamente plano; así, los meandros del río atenuarán su pendiente y velocidad. La única actividad permitida es el cruce peatonal.

Luego está el cauce para la crecida de hasta 20 años, con anchos entre ro y 30 metros. Los taludes tienen hasta Io \% de inclinación; en ellos crece vegetación endémica (principalmente Brea y gramíneas) y sólo se permiten actividades de paseo.

Después está la sección para la crecida centenaria. Los taludes - con una inclinación máxima de $20 \%$ se protegen con rocas para evitar la erosión durante las crecidas. Hacia el centro, los taludes tienen una fundación de $2 \mathrm{~m}$ de profundidad para evitar la ampliación del cauce central. Los revestimientos deben permitir la caminata y pueden tener vegetación nativa o plantas de baja altura; también puede haber trabajos de suelo (veredas, rampas, etc.) que no estorben el flujo del agua. Se permiten actividades de contemplación, paseo, descanso o juegos sin implementos fijos.

Finalmente, la sección tiene un borde libre de i $\mathrm{m}$ para contener eventualidades (olas o elementos que sobrepasen el nivel de agua de la mayor crecida). Dado que el ancho de la sección completa es de entre 60 y $80 \mathrm{~m}$, este borde adicional permitió contener casi el doble de caudal proyectado, tal como ocurrió con las crecidas de 2015 y 2017.

\section{Parque}

El parque se divide en tramos entre puentes, cada uno con un carácter propio. El primero, construido en el año 2013, tiene un carácter cívico. En el tramo dos, en uso desde enero de 2018 , las riberas tienen diverso carácter: en la norte hay paseos que unen plazas, ferias y espacios de juegos familiares; en la sur, el antiguo depósito de relaves mineros se resuelve con un montículo que funciona como mirador hacia el río, el parque, la ciudad y los cerros que rodean el valle. Para 

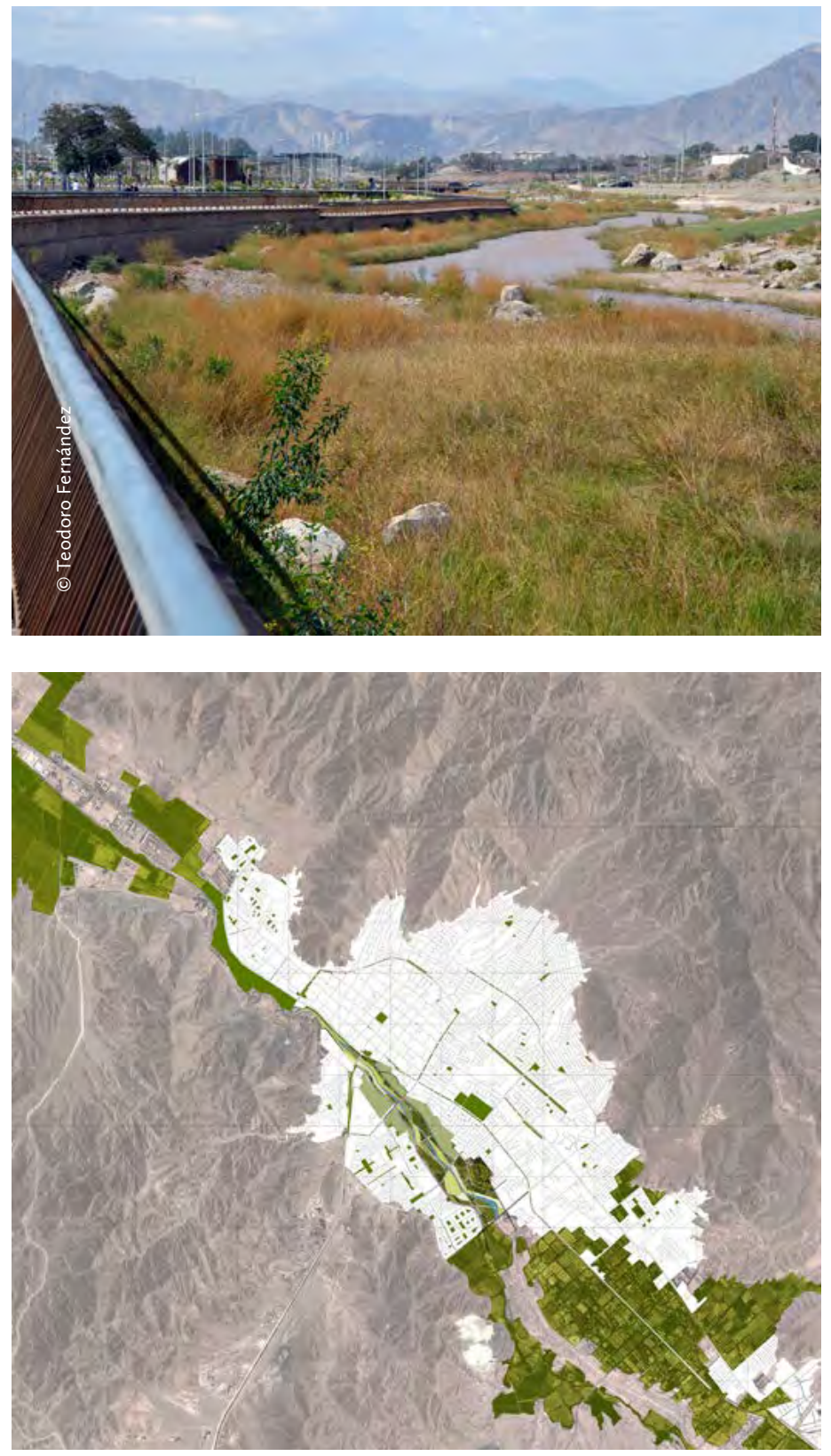

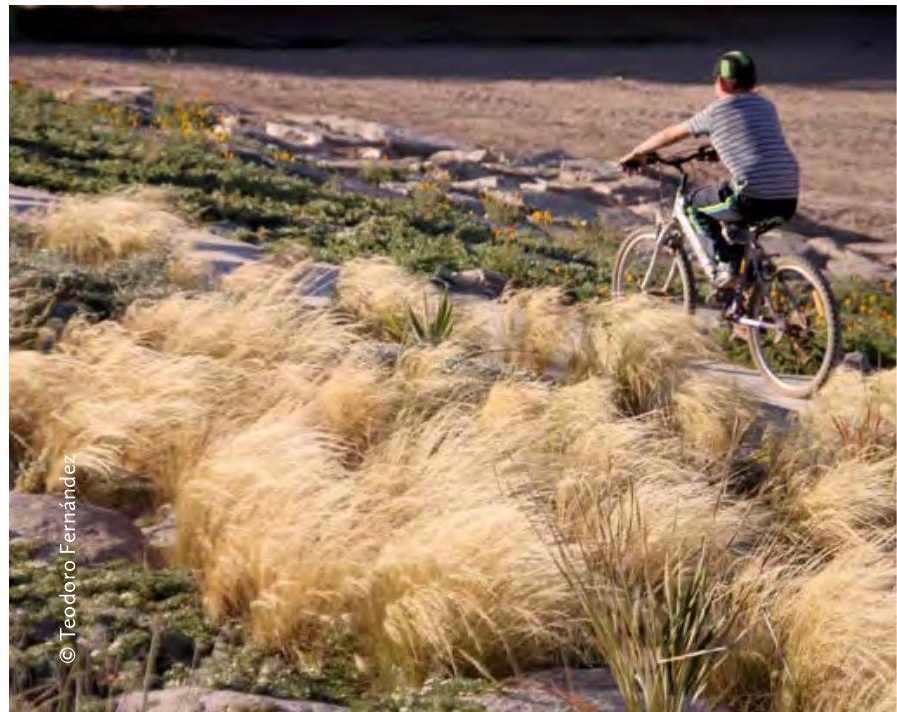

Ubicación del proyecto en la

ciudad de Copiapó. / Project's

location at Copiapó.

S. E. / N. S. incorporar el relave al espacio público (considerando que el material es altamente contaminante), se realizó un 'encapsulamiento' que protege tanto las napas subterráneas como el aire.

En la ribera norte del tramo tres hay un auditorio al aire libre, canchas, pérgolas y espacios informales de juego; la ribera sur se conforma por pequeñas plazas y espacios de juegos de barrio. El tramo cuatro incorpora, por la ribera norte, el parque El Pretil junto a estacionamientos, una laguna/humedal e instalaciones para la media luna existente. En la ribera sur se anexa el proyecto de estadio Atlético Municipal, transformando la zona en un amplio conjunto deportivo. Este tramo será la siguiente etapa en construirse.

Además de pavimentos que aseguran la accesibilidad universal, diseñamos una serie de elementos 


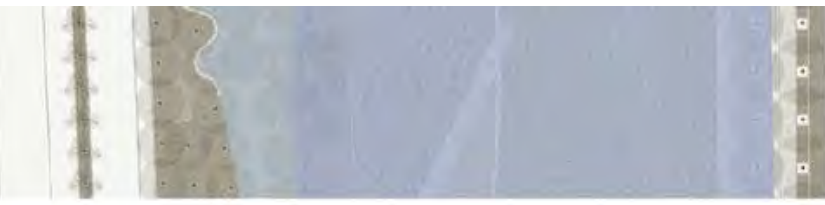

Eventualities
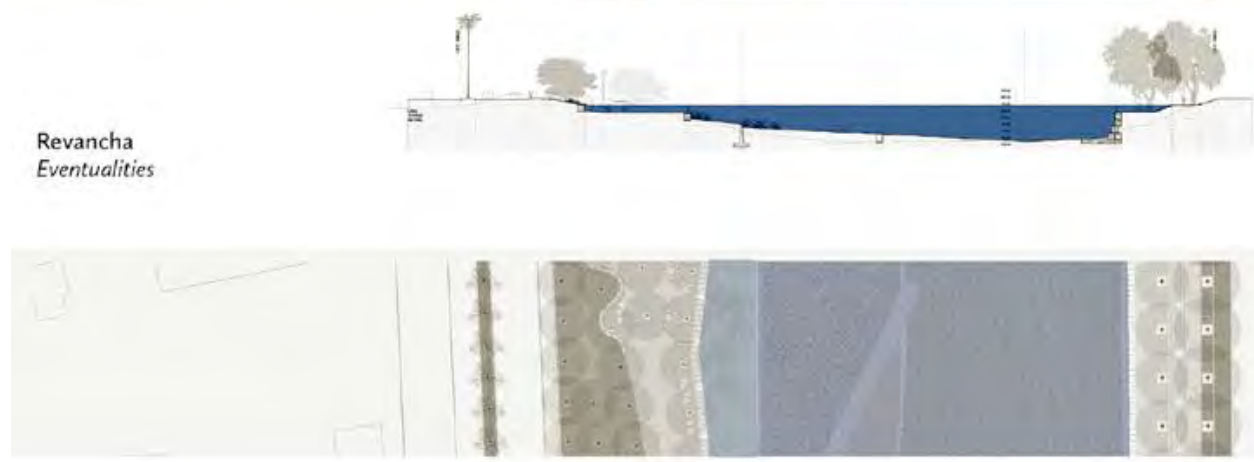

Crecidas 200 años

200 years floods
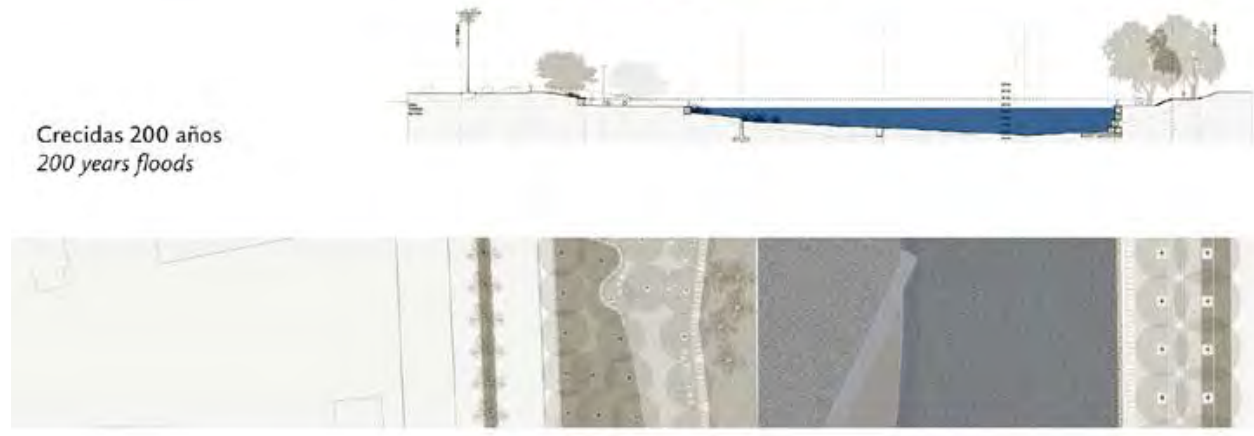

Crecidas 100 años

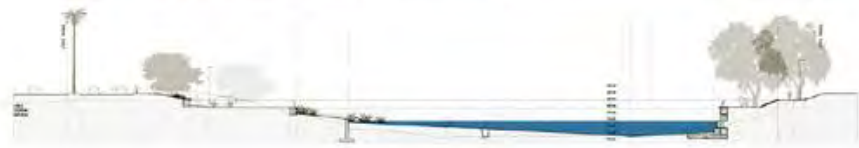

100 years floods

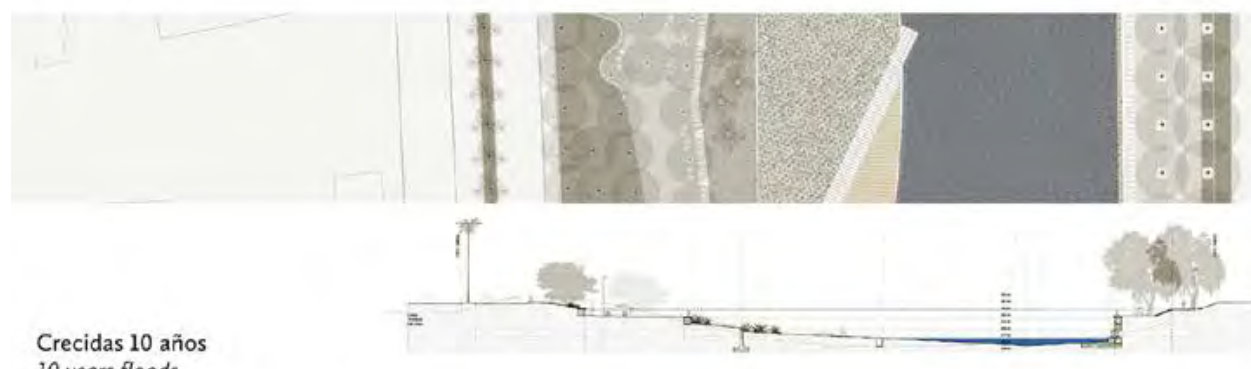

10 years floods

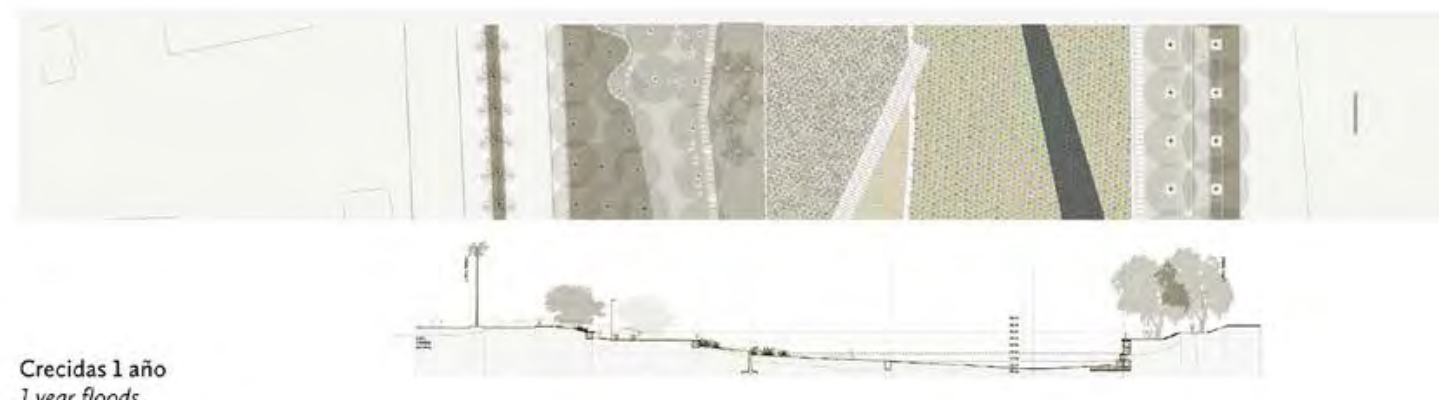


Planta pavimentos / Pavement plan

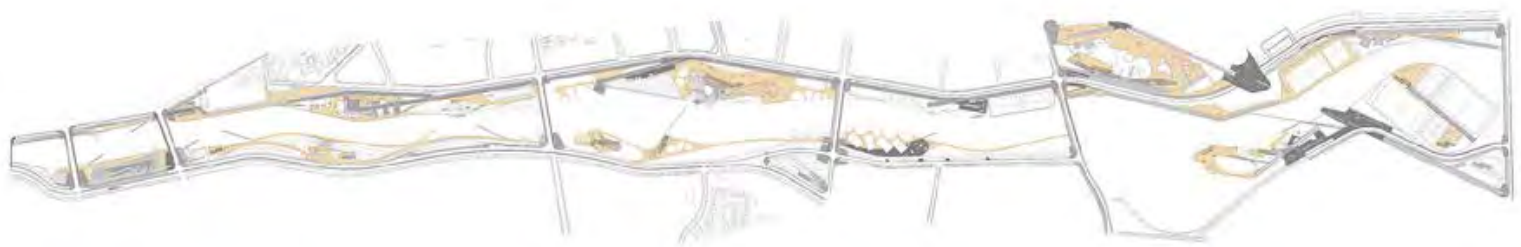

Planta general / General plan

E. / S. 1:5.000

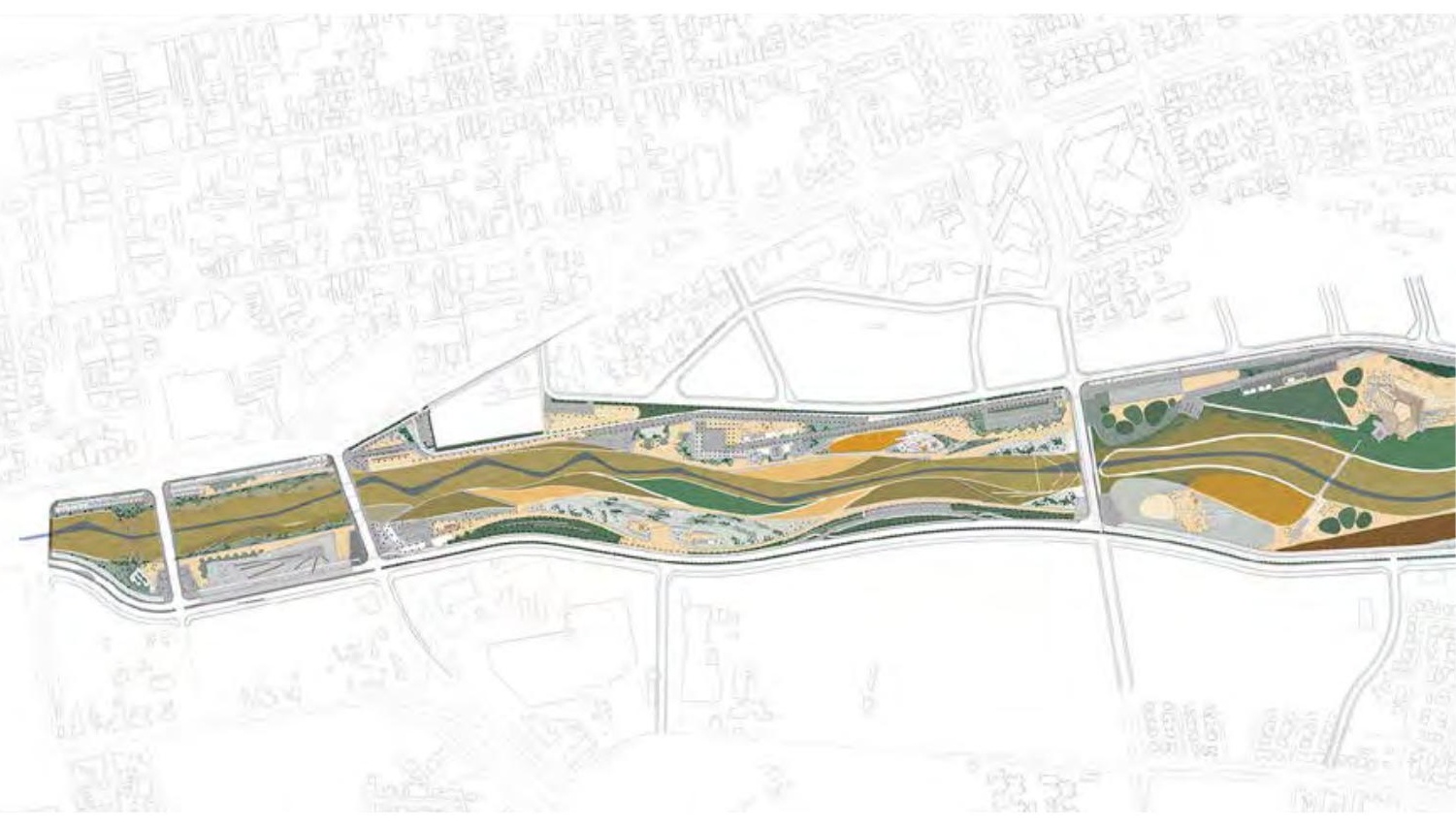

Planta suelos / Grounds plan

E. / S. 1: 10.000

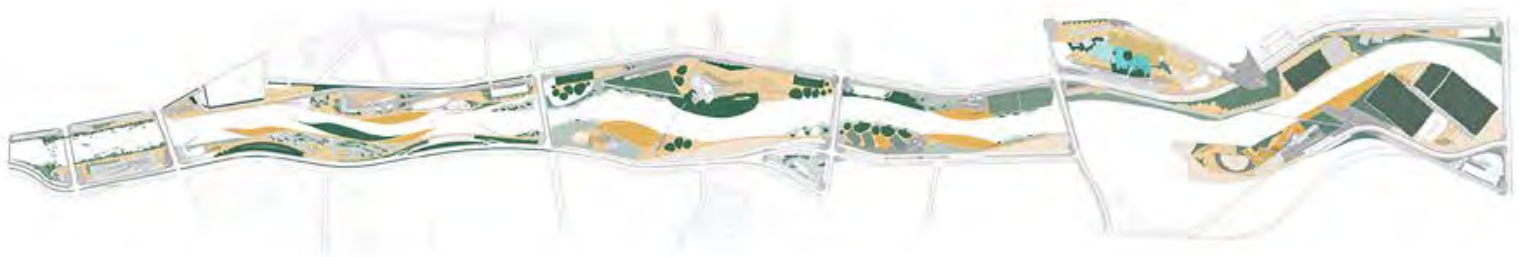



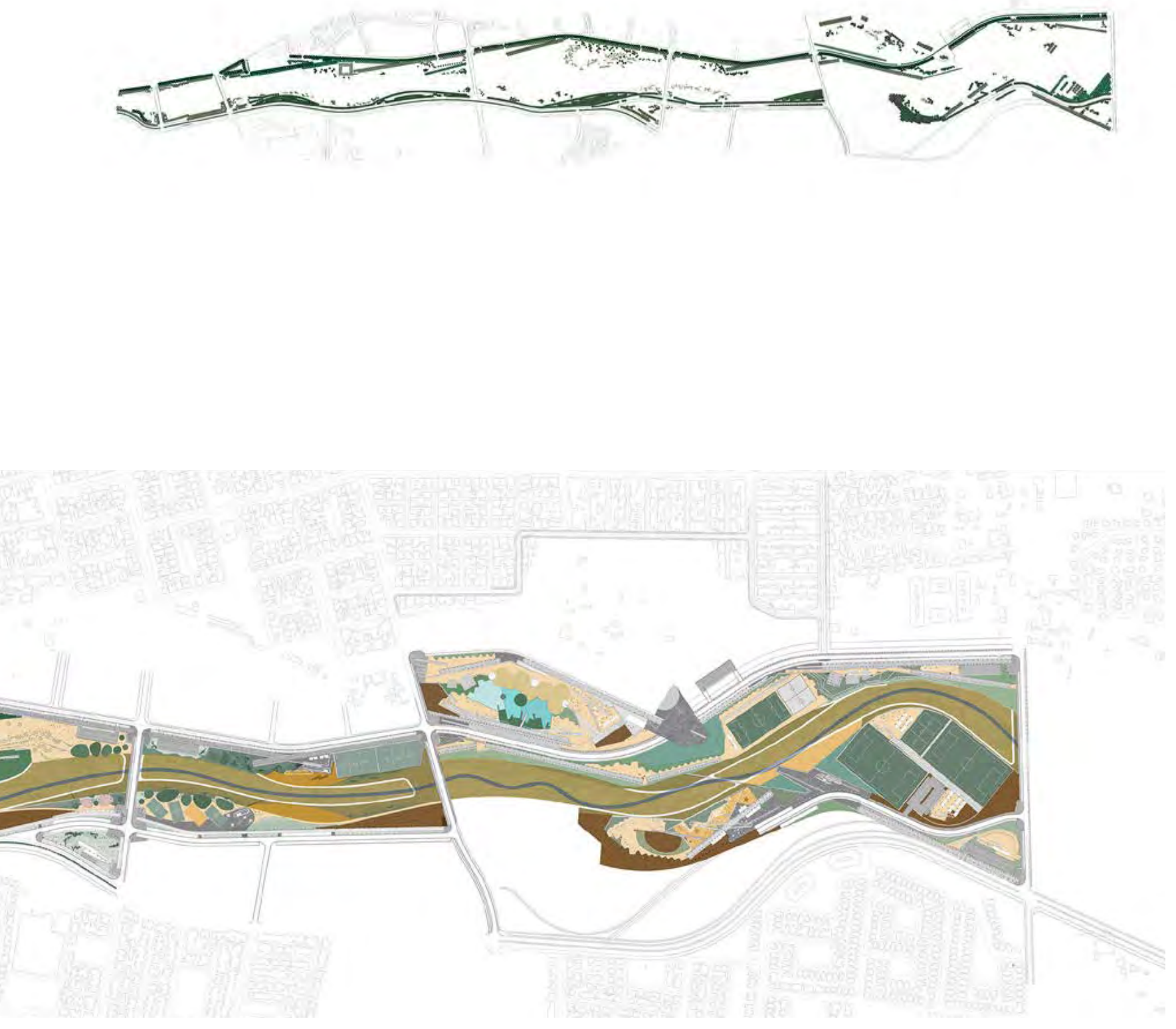

Planta caja del río / Riverbed plan

E. / S. 1: 10.000

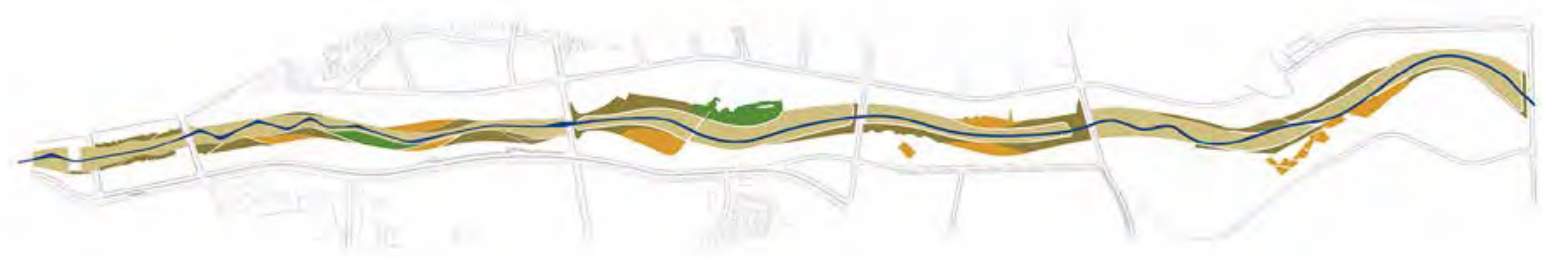


Detalles / Details E. / S. 1: 125

\section{LEYENDA}

1. Piedras D20 cm

2. Pavimento asfáltico $e=5 \mathrm{~cm}$

3. Base estabilizada $e=20 \mathrm{~cm}$

4. Tierra compactada $\mathrm{e}=30 \mathrm{~cm}$

5. Solera tipo «a»

6. Pavimento asfáltico vehicular

7. Solera ciclovía prefabricada

8. Mortero de pega, espesor variable
9. Tierra para plantar

10. Terreno natural

11. Pieza prefabricada H.A.

12. Remate gavión

13. Gavión existente

14. Maicillo e $=8 \mathrm{~cm}$

15. Geotextil

16. Ripio e $=8 \mathrm{~cm}$

17. Solera T prefabricada
18. Grada prefabricada de H.A.

19. Ripio e $=10 \mathrm{~cm}$

20. Relave perfilado

21. Gavión nuevo

22. Base para gavión

23. Solerilla canto recto $20 \times 6 \mathrm{~cm}$

24. Pieza prefabricada de H.A.

25. Banco Z

26. Radier base para anclaje
27. Ripio e $=15 \mathrm{~cm}$

28. Remate gavión

29. Baldosa colonial $40 \times 60 \mathrm{~cm}$

30. Baldosa $40 \times 40 \mathrm{~cm}$

31. Base estabilizada $20 \mathrm{~cm}$

32. Espejo de agua

33. Arena $40 \mathrm{~cm}$

Km. 450

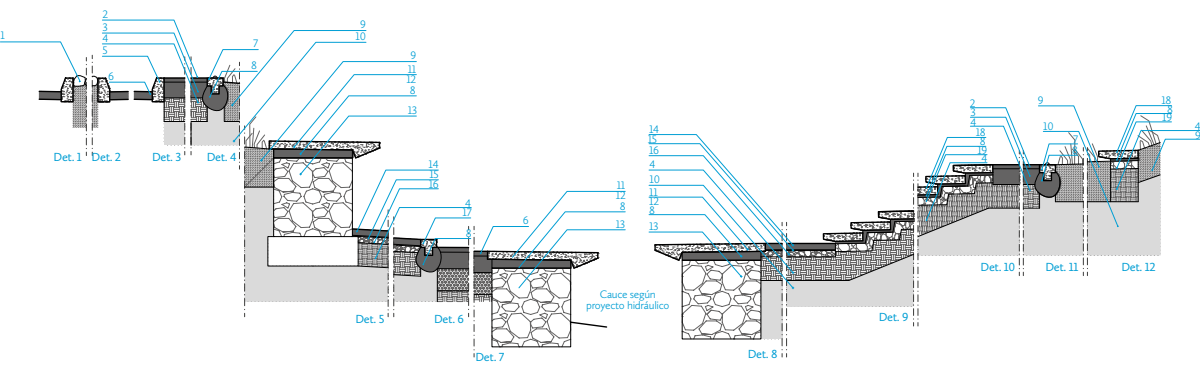

Km. 720

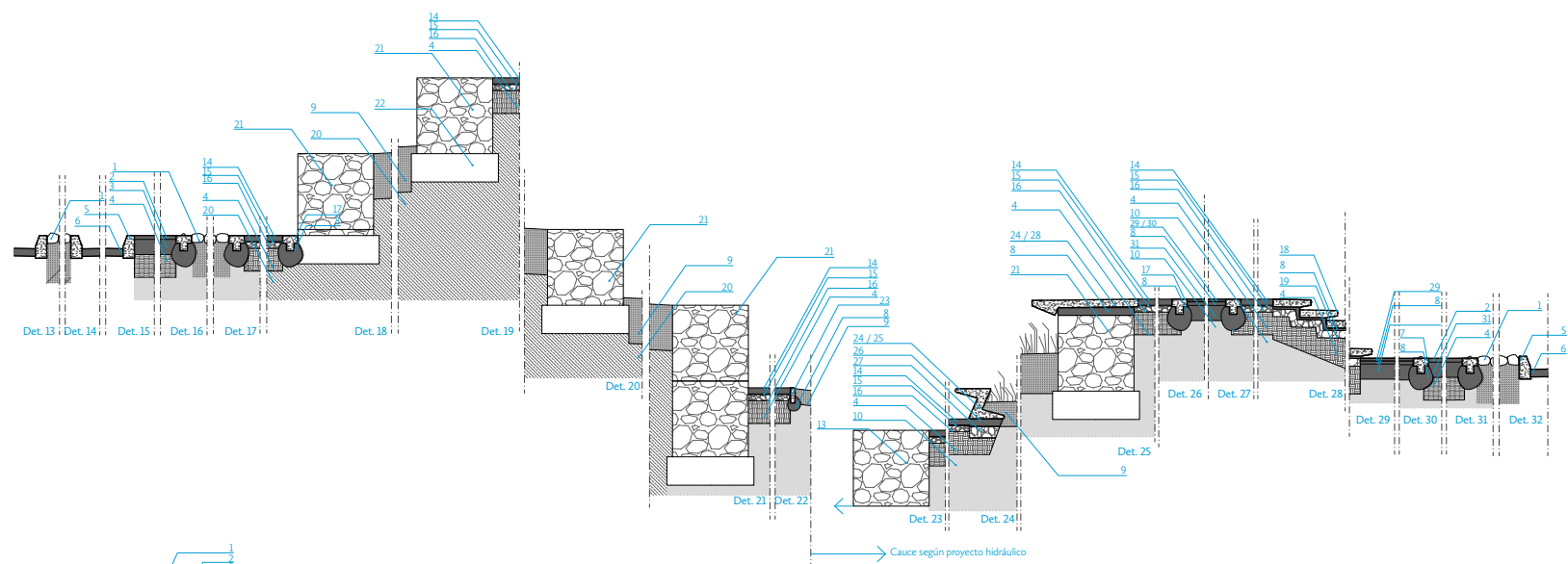

Km. 800
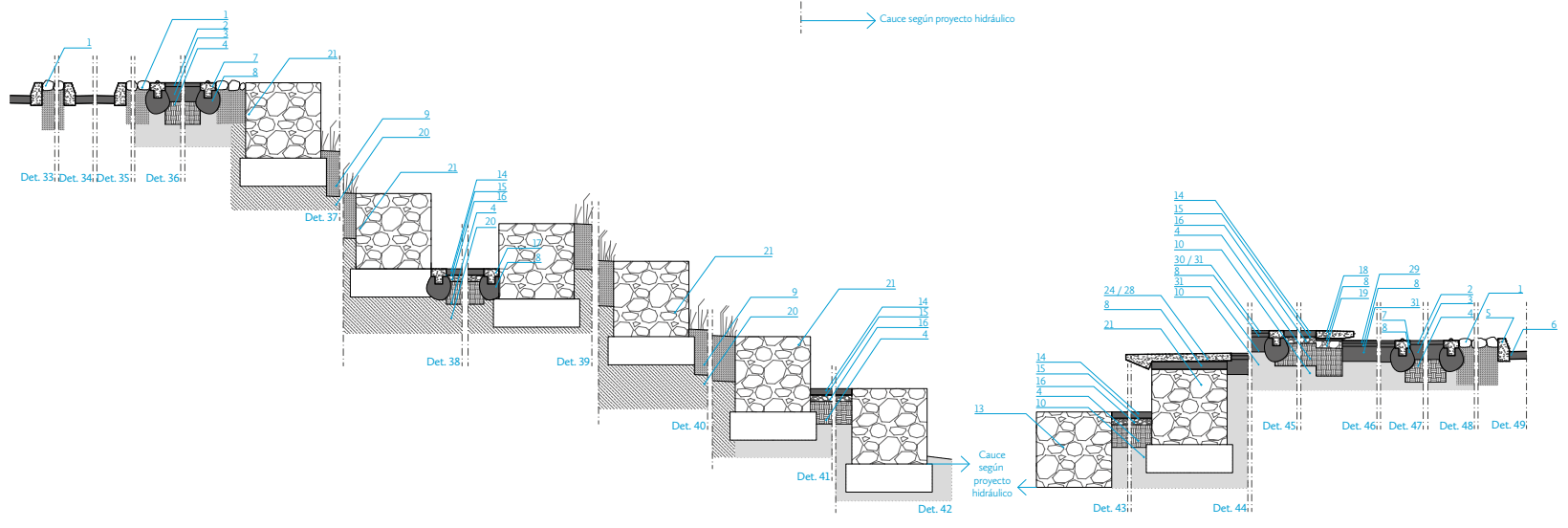

Km. 900

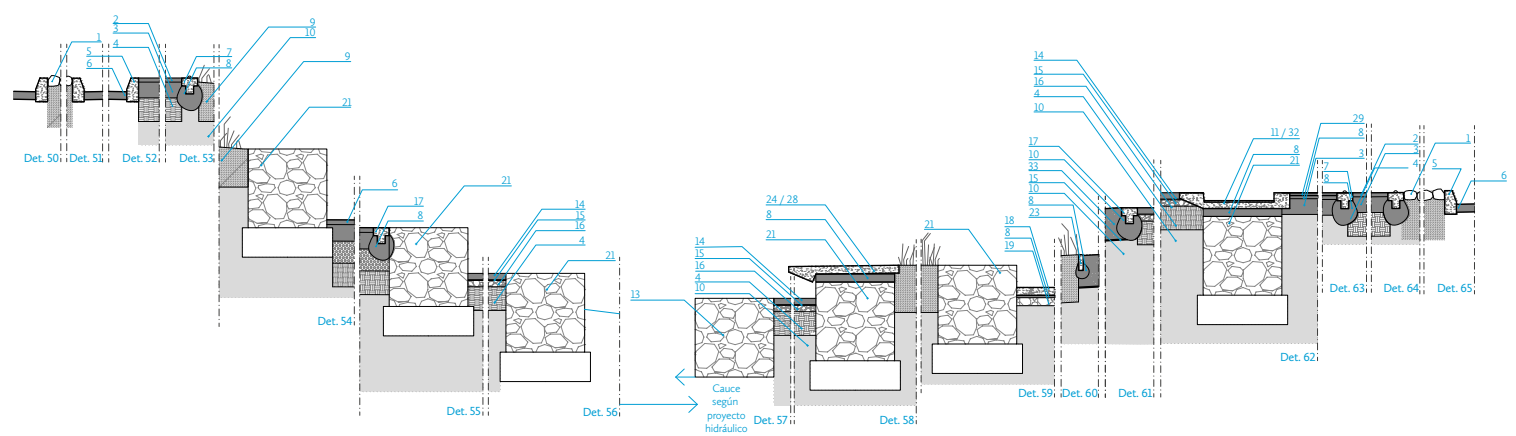


Cortes transversales / Cross sections

E. / S. 1:1.000

Km. 342

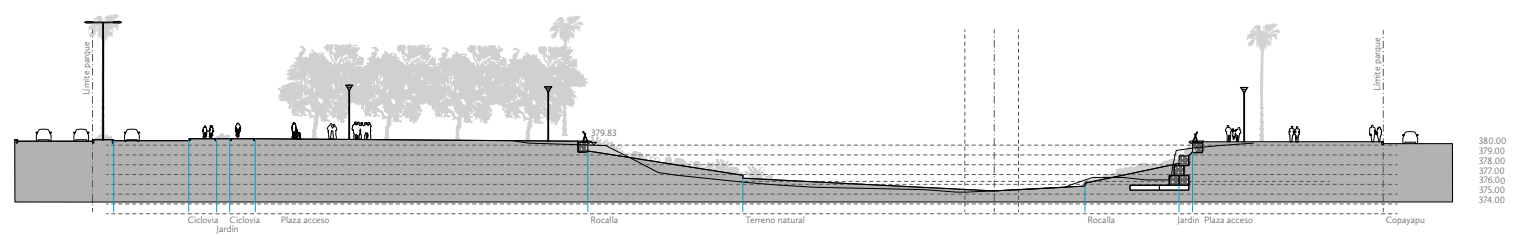

Km. 450

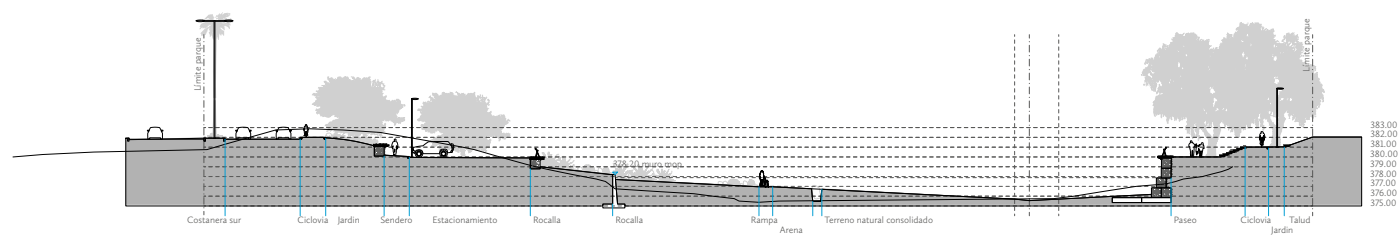

Km. 520

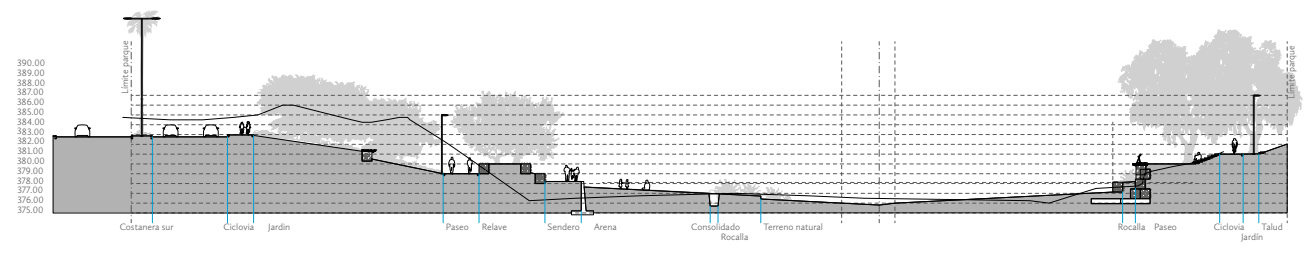

Km. 580

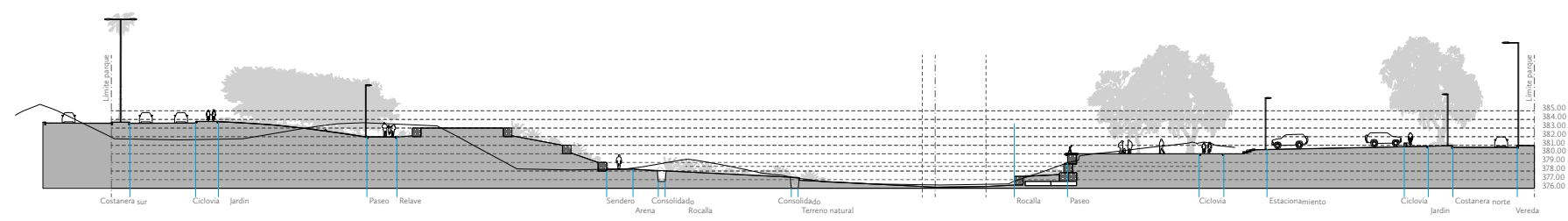

Km. 630

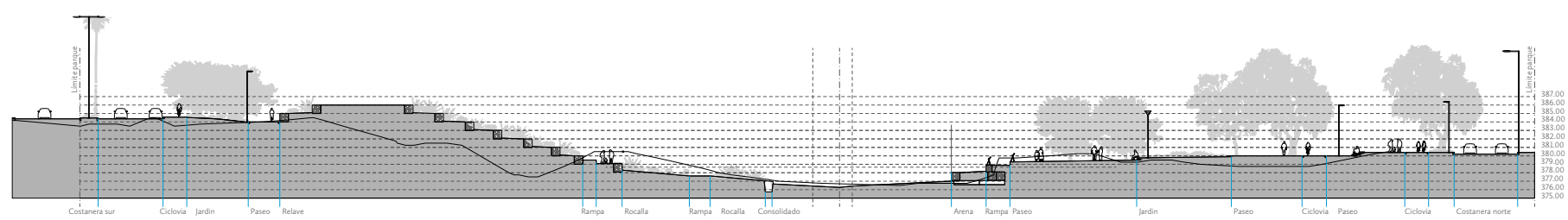


Km. 720

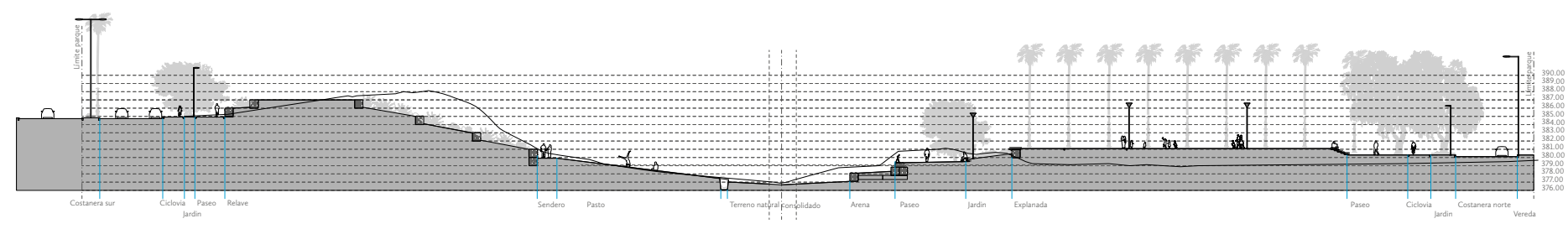

Km. 800

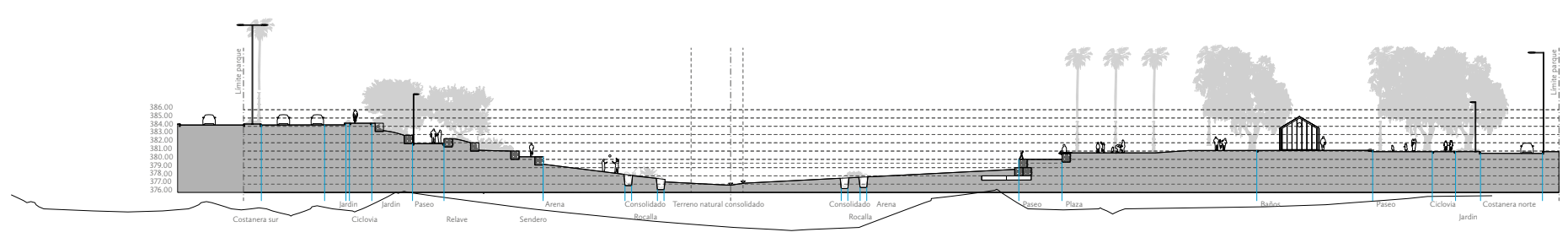

Km. 900

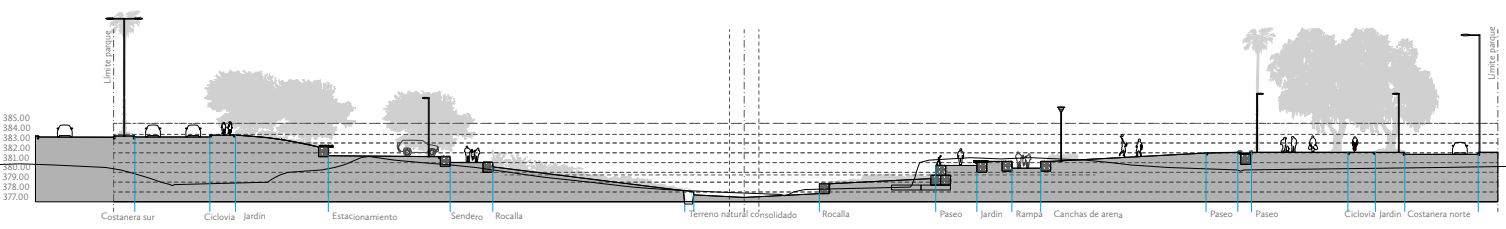

Km. 930

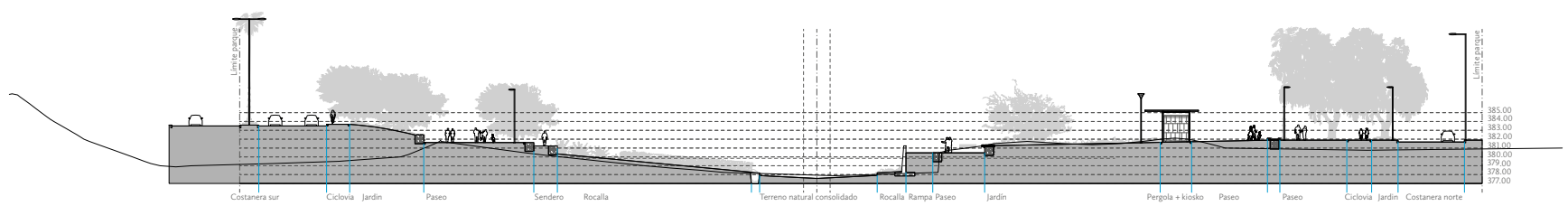

Km. 1.082

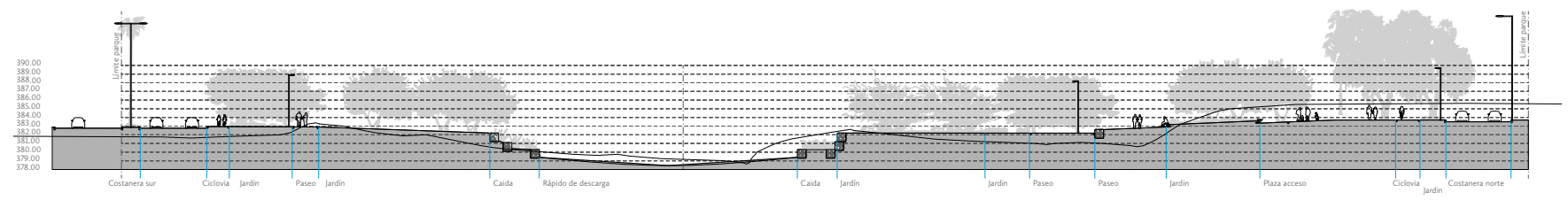




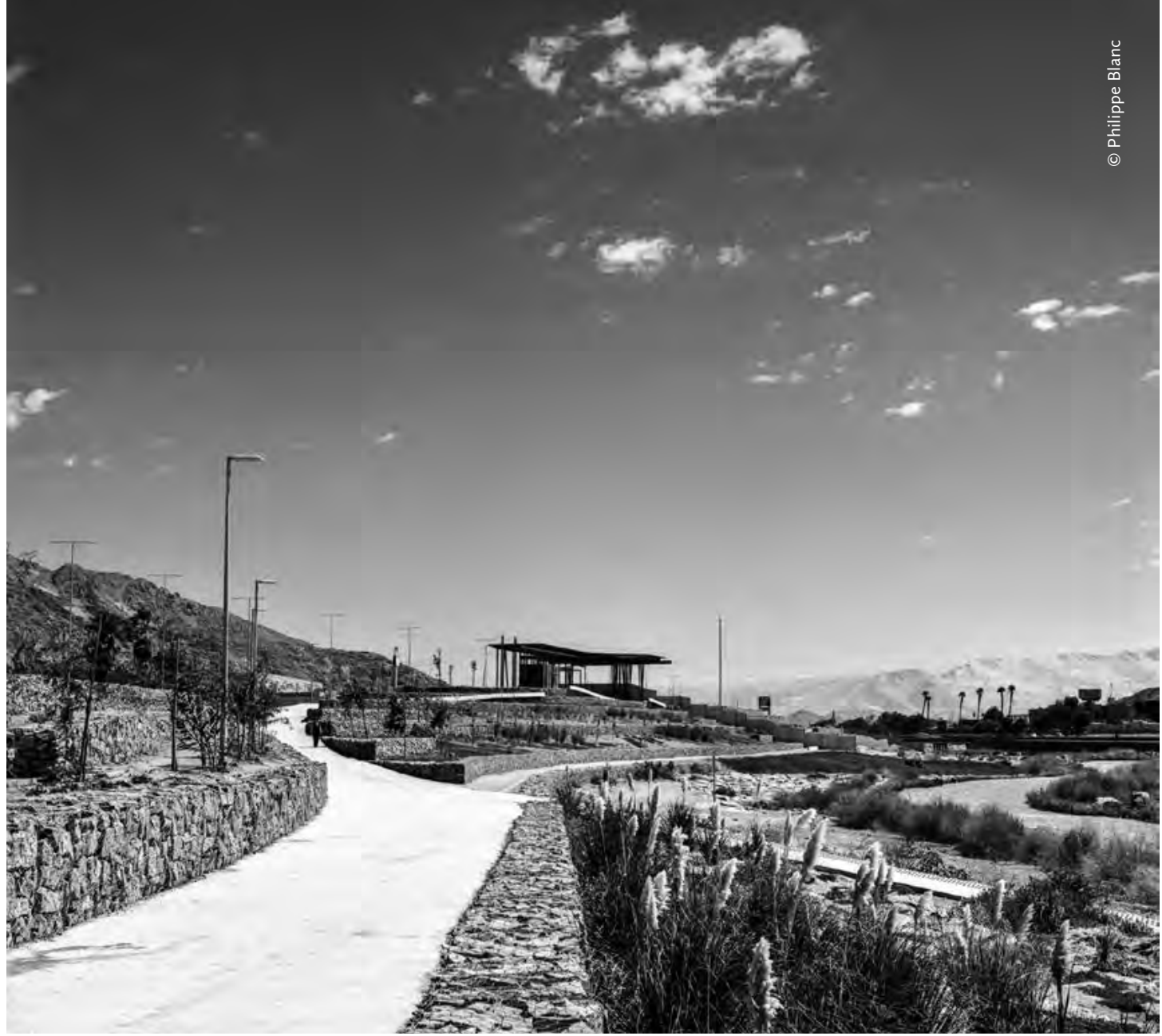

PARQUE KAUKARI DEL RÍO COPIAPÓ

KAUKARI PARK AT COPIAPÓ RIVER

Arquitectos / Architects: Teodoro Fernández Arquitectos

Teodoro Fernández, Paulina Courard, Macarena Gaete, Milva Pesce, Benjamín López

Colaboradores / Contributors: Claudio Torres, Alejandra Vásquez Ubicación / Location: Copiapó, Chile

Cliente / Client: Seremi Vivienda y Urbanismo, Región de Atacama Ingeniería hidráulica / Hydraulic engineering: Bonifacio Fernández Ingeniería estructural / Structural engineering: Romina Aranda Cálculo Estructural / Structural design: Antonio Ramírez Urra Instalación eléctrica /Electrical system: PROINGEL, Mauricio Camus Instalación sanitaria / Mechanical engineering: Patricio Moya
Diseño Urbano / Urban Design: Luis Eduardo Bresciani, Arquitecto Urbanista

Iluminación / Lightning: Limarí Ligthing Design, Pascal

Chautard Iluminación

Consultor Agronómico / Agronomic consultant: Ximena Nazal Presupuesto / Budget: $40 \mathrm{us} / \mathrm{m}^{2}$

Superficie construida / Built surface: $600.000 \mathrm{~m}^{2}$

Año de proyecto / Project year: 2011-2013

Año de construcción / Construction year: 2013-2018

Fotografías / Photographs: Philippe Blanc, Rodrigo Opazo

\section{Teodoro Fernández Arquitectos}

Desde 1992, Teodoro Fernández Arquitectos consolida una línea de desarrollo de proyectos de paisaje para la zona central de Chile desde la perspectiva del cuidado del agua, el afianzamiento de los suelos y la integración de criterios biodinámicos. Entre sus obras se encuentran el parque del fundo Quitralmán (Mulchén, 200o), los corredores ecológicos para la viña Los Robles (Nancahua, 2003), las áreas verdes de la urbanización La Reserva (Santiago,2003) y el paisajismo para la viña Chocalán (Melipilla, 2004). Se ha adjudicado además el primer premio en los concursos para el Parque Inés de Suárez (Providencia, I992), Parque Bicentenario (Vitacura, 1999-2010) y la remodelación del Parque Quinta Normal. Actualmente desarrolla el proyecto Parque Borde Costero de Antofagasta, primer premio en concurso adjudicado en 2017. 


\section{Contener, restaurar, conectar: el paisaje como infraestructura}

\section{OSVALDO MORENO}

Profesor Asistente,

Jefe de programa de Magíster en Arquitectura del Paisaje MAPA

Escuela de Arquitectura, Pontificia Universidad Católica de Chile, Santiago, Chile

Históricamente los ríos urbanos han planteado importantes desafíos para la planificación de las ciudades en Chile, en especial cuando su presencia física ha estado acompañada de regímenes hidrológicos inestables y cambiantes, como ocurre en los ríos del norte y centro de Chile dada la condición de torrente estacional que en general los caracteriza. Desde las primeras canalizaciones y tajamares construidos durante la colonia y las primeras décadas republicanas, hasta las actuales defensas fluviales, costaneras y espacios públicos proyectados en torno a sus márgenes, los ríos han demandado una constante atención de diversos campos técnicos orientados a su dominación y aprovechamiento. Sumado a lo anterior, el panorama contemporáneo presenta nuevos retos que no sólo refieren a una dimensión técnica operativa, sino a una concepción cultural y ambiental que, desde esferas intelectuales, ciudadanas y políticas, determina la necesidad de una aproximación más integral hacia el manejo de los ríos urbanos como sistemas socioecológicos complejos ${ }^{1}$, en creciente estado de vulnerabilidad producto de las actividades antrópicas derivadas de procesos de industrialización y expansión urbana acontecidos en las últimas décadas. De manera crítica, el deterioro de los lechos, riberas y ecosistemas asociados a ríos urbanos han comprometido sus capacidades para contener inundaciones y aluviones que, de forma cada vez más frecuente, afectan a territorios y comunidades localizadas en sus inmediaciones.

El río Copiapó constituye un ejemplo paradigmático que, en su historia reciente, expresa gran parte de estas problemáticas. Debido a la sistemática explotación de sus aguas para el desarrollo de la industria minera, el tradicional paisaje de sus riberas - que articuló por siglos la vegetación riparia, los cultivos agrícolas y usos recreativos - se sustituyó en poco más de 30 años por una secuencia de faenas extractivas, depósitos de escombros y relaves mineros. En este escenario, a partir del año 2oII comenzó a desarrollarse el proyecto Parque 

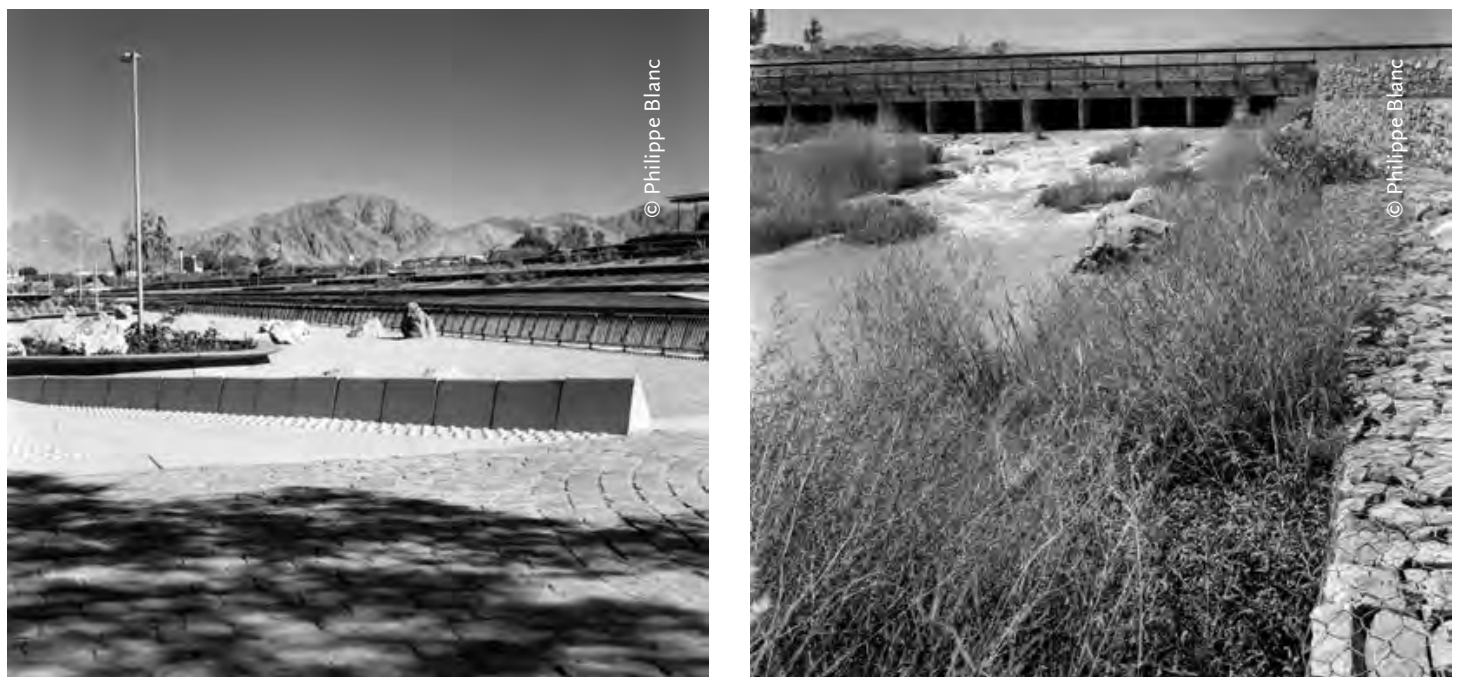

Kaukari, a cargo de Teodoro Fernández Arquitectos. A través de sus 6o hectáreas el Parque pretende recuperar el río Copiapó en su condición de espacio público, de sistema hidrológico y de corredor verde, mediante el diseño de paseos de borde, plazas aterrazadas, revegetación de riberas y arboledas, con especial atención en el uso de especies aptas para subsistir en contextos áridos y de materialidades coherentes con la estética y cultura del desierto. En términos formales, uno de los aspectos más destacables es la configuración de diversas conexiones para acceder al lecho mediante rampas, escaleras y taludes, ofreciendo una experiencia que revitaliza esa relación ancestral de las comunidades con el río, esta vez en un contexto de urbanidad que lo reclama como espacio público.

En marzo de 2015, fuertes precipitaciones generaron un inédito aumento de caudal del río Copiapó, equivalente a un periodo de retorno de más de ıoo años, acompañado de diversos aluviones que afectaron a gran parte de la ciudad. El fenómeno al cual se vio expuesto el Parque Kaukari redefinió los alcances de este proyecto y de la propia incumbencia disciplinar de la arquitectura del paisaje en términos de su aporte a la gestión de riesgo y resiliencia urbana ${ }^{2}$. Trascendiendo las operaciones accesorias que comúnmente concurren en proyectos de paisaje y espacio público en ciudades regionales, Kaukari remarca el valor de las operaciones esenciales que, como señalan diversos autores, convergen en la idea de «paisaje como infraestructura» ${ }^{3}$. Es aquí, en esta discusión acerca de lo estrictamente necesario, donde se instala la reflexión acerca del enfoque de diseño de paisaje que puede prevalecer ante escenarios de cambios, vulnerabilidades y desastres. Desde este enfoque, el paisaje se devela como potencial infraestructura del territorio, generando capacidades adaptativas a través de proyectos que permitan la articulación de los sistemas naturales y antrópicos, la evolución de sus componentes en el tiempo y el desarrollo de programas flexibles que, aun así, promuevan la evocación de los valores estéticos y culturales del paisaje. ARQ 

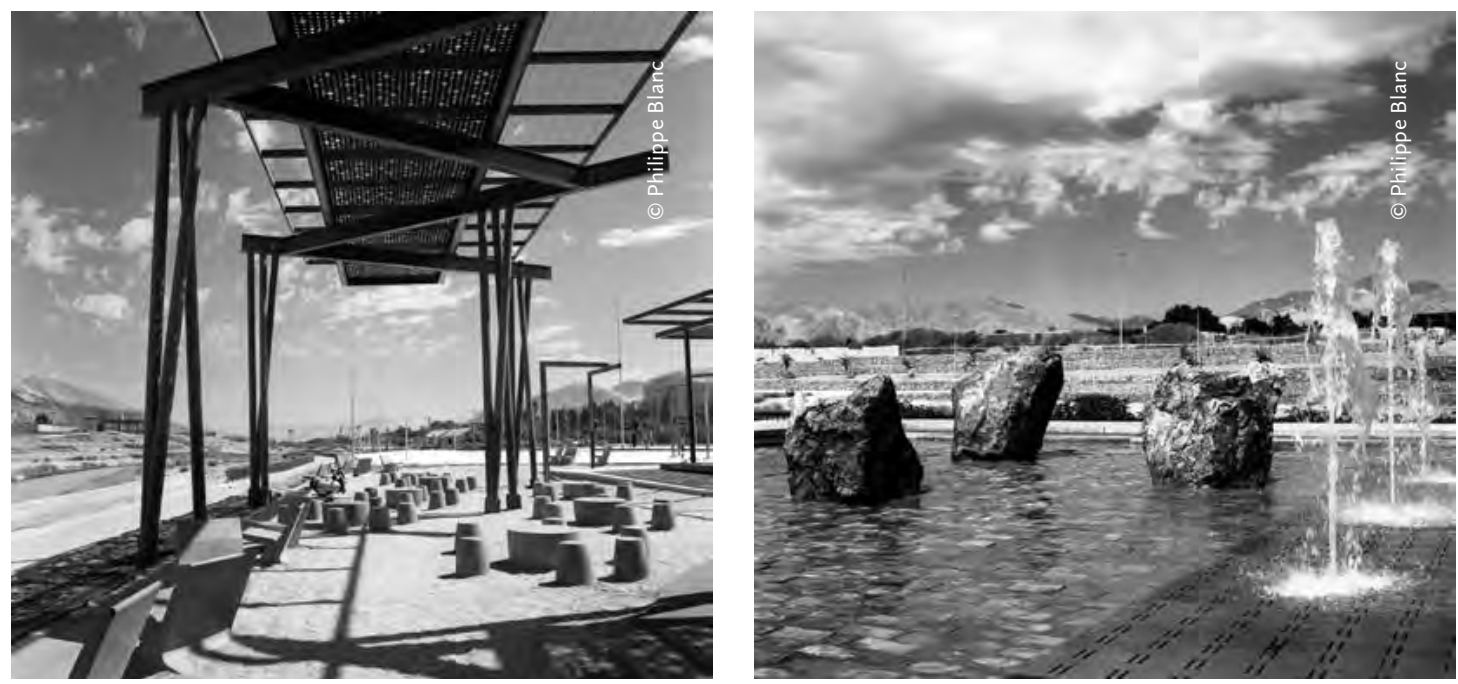

\section{Notas / Notes}

I Un sistema socioecológico describe un sistema territorial complejo, conformado por la combinación de elementos antrópicos y naturales que establece una dinámica ecológica hibrida donde interactúan variables sociales y ambientales. (Ostrom, 2009).

2 En términos generales el concepto de resiliencia refiere a la capacidad de un sistema para adaptarse a los cambios que acontecen en un determinado contexto y asumir flexibilidad en situaciones límite, para sobreponerse a ellas (Kreimer et al., 2003; Vale \& Campanella, 2005, Moreno, 2013).

3 Bajo esta perspectiva, el paisaje y sus componentes pueden ser comprendidos como una potencial red estructurante del territorio y la ciudad. Diversos autores (Belanguer, 2017; Waldheim, 2016; Corner, 20I4; Reed \& Lister, 20I4; Hung, 20II) discuten acerca del rol del Paisaje como Infraestructura del territorio.

\section{Bibliografía / Bibliography}

B ELANG ER, P. Landscape as Infrastructure: A Base Primer. New York: Routledge, 2017

HUNG, Y. Landscape Infrastructure: Case Studies by swa. Basilea: Birkhäuser Architecture, $201 \mathrm{I}$.

KREIMER, A.; ARNOLD, M. \& CARLIN, A. (ed.) Building Safer Cities. The Future of Disaster Risk. Washington D.C.: The World Bank Disaster Management Facility, 2003.

moreno, O. «Paisaje, Riesgo, Resiliencia». Forum de Sostenibilidad Cátedra unESCO, 6 (2013), I7-30. os т rom, E. A «General Framework for Analyzing Sustainability of Social-Ecological Systems». Science, 5939 (325, 2009), 4I9-422. REED, C.; LIST E R N. Projective Ecologies. Harvard University Graduate School of Design. Actar, 2014

VALE, L.; CAM PAN E Lla, T. The resilient city. How modern cities recover from disaster. New York: Oxford University Press, 2005. WA L Dheim, C. (Ed.) Landscape as Urbanism. New York: Princeton Architectural Press, 2016

\section{Osvaldo Moreno}

<omorenof@uc.cl>

Arquitecto, Universidad de Chile, 2003. Magíster en Paisaje, Medioambiente y Ciudad, 2007 y Doctorando en Arquitectura y Urbanismo, Universidad Nacional de La Plata. Becario Programa ALFA Pehuén, 2005-2006 y Becario Erasmus Mundus European Commission, 2013. Autor de diversos artículos de revista y capítulos de libros en México, Argentina, España y Chile. Jefe de Magíster en Arquitectura del Paisaje uc y Profesor Asistente Escuela de Arquitectura, Pontificia Universidad Católica de Chile. Profesor de la Facultad de Arquitectura y Urbanismo, Universidad de Chile. 